\title{
D. H. Lawrence. México, la utopía imposible
}

\author{
Armando Pereira \\ Instituto de Investigaciones Filológicas \\ Universidad Nacional Autónoma de México \\ pereira@unam.mx
}

\begin{abstract}
Resumen: D. H. Lawrence encontró en México el país que podía hacer realidad uno de los anhelos más importantes de su vida: comprar un rancho y construir una especie de comuna, en la que él, su mujer y sus amigos más cercanos pudieran vivir de una manera creadora y libres de la racionalidad opresiva, el afán técnico y la obsesión por el progreso que habían devorado a Europa. Ese proyecto solo logró realizarlo no en la vida, sino en una novela: La serpiente emplumada. Es al análisis de esa novela y también de un libro de cuentos sobre México, en los que despliega una visión abigarrada, contradictoria y desengañada sobre el país y su gente, al que dedicamos este ensayo.
\end{abstract}

Aвstract: D. H. Lawrence found in Mexico the country where he could realize one of the more important desires in his life: to buy a ranch and build there a sort of commune, where he, his wife and his closest friends could live in a creative way and free of the oppressive rationality, anxiety of technique and obsession of progress that had swallowed Europe up. That project he could only realize not in life, but in a novel: The Plumed Serpent. In this essay I try to analyze this novel and another short stories book, in which Lawrence expose his variegated, contradictory and disillusioned points of view about Mexico and its people.

PALABRAS ClAVE: utopía, barbarie, Quetzalcóatl, indígena, salvaje.

KeYwords: utopia, cruelty, barbarism, Quetzalcoatl, Indian, savage.

Entre 1923 y 1925, Lawrence hizo tres viajes a México, aunque su estancia en el país a lo largo de esos tres años no rebasó los once meses. Además de breves estancias en la ciudad de México, recorrió la costa occidental desde Sonora hasta Oaxaca. Lo que buscaba insistentemente aquí, como ya lo había hecho antes en el sur de Estados Unidos, era encontrar el lugar propicio para realizar el ideal más consistente en toda su vida: un sueño, una utopía, que la vieja y exhausta Europa no le ofrecía la posibilidad de realizar. América era ese nuevo continente que todavía no había sido devastado por la fría racionalidad de Occidente, por su fagocitante compulsión técnica, por esa obsesión de progreso 
que no sabía responder a preguntas tan simples como ¿para qué o hacia dónde? América era entonces, para Lawrence, esa ilusión, de raigambre spengleriana, que alimentaría también las fantasías de una vida nueva, más íntegra y más humana en muchos otros escritores europeos. Ante la inevitable "decadencia de Occidente", ante la necesidad de salvar esa esperanza de una espiritualidad que se veía amenazada por el avance de un pensamiento utilitarista y tecnocrático, surge en Lawrence el anhelo de América como el paraíso terrenal, como la tierra redentora. En una carta del 26 de octubre de 1915 (un poco antes del interdicto de su novela The Rainbow en Inglaterra), escribe a Harriet Monroe:

Tengo que ver América: aquí el otoño de la vida se ha iniciado, la caída: somos apenas algo más que fantasmas en la niebla, nosotros, que nos apartamos del flujo de la muerte. Tengo que ver América. Creo que solo puedo hallar esperanzas allá. Creo que allá la vida surge de sus raíces, cruda pero vital. Aquí todo el árbol de la vida está muriendo. Es como estar muerto: el submundo. Tengo que ver América. Creo que está empezando, y no terminando (Huxley: 262).

Lo que el viajero inglés buscaba en tierras americanas era fundar una comunidad de hombres libres, desasidos de la racionalidad mecanicista que infestaba Europa, capaces de vivir plenamente todas las instancias intelectuales, afectivas y libidinales que la estrecha moral occidental imposibilitaba (y cuyos inquisidores, en Inglaterra, habían prohibido la publicación de su novela). Eso solo sería posible en América, ese Nuevo Continente que todavía no imponía barreras férreas a la libre manifestación del espíritu, donde el hombre podría realizar en plenitud su voluntad interior.

En 1922, vuelve a resurgir en Lawrence la idea de fundar una comuna de hombres libres en América, con ocasión del ofrecimiento de Mabel Dodge de formar parte de su colonia de escritores y artistas en Taos, Nuevo México. Pero Nuevo México, y Taos en particular, les desagradaba a los Lawrence, no se encontraban a gusto allí, sobre todo porque la relación entre Frieda y Mabel no era muy amable. Y deciden, en la primavera de 1923, continuar el viaje hacia tierras mexicanas, donde, ahora sí, están seguros de fundar su anhelada colonia y traer a sus amigos ingleses a vivir con ellos el largo sueño de su juventud. Después de recorrer la costa occidental del país, Lawrence decide que 
ha encontrado en Jalisco, a las orillas del lago de Chapala, el lugar ideal para llevar a cabo su utopía. Y no duda en sentarse enseguida a la máquina y escribirle una larga carta (Guadalajara, 17 de octubre de 1923) a Catherine Carswell:

México tiene un cierto misterio de belleza para mí, como si los dioses estuvieran aquí. Ahora, en octubre, los días son tan puros y bellos que producen una especie de encantamiento. Como si alguno de los dioses oscuros fuera aún joven. Desearía poder construir un pequeño rancho, donde pudiéramos tener nuestras pequeñas casas de adobe y comenzar una nueva vida; y que usted pudiera venir con Don y John Patrick. [...] Es extraño, recorrí toda la costa del pacífico pensando: es mejor regresar a Inglaterra. Y luego, una vez que hube cruzado la barranca de Ixtlán, era aquí, donde los dioses pueden ser espantosos pero son jóvenes, donde quería estar, aquí, en México, en Jalisco. Y hay lugar, lugar para todos nosotros (Lawrence 1970: 93-94).

Esta perentoria solicitud a Catherine Carswell, Lawrece la hará extensiva a varios amigos: ha encontrado un lugar en Jalisco para construir un rancho y comenzar una vida nueva, "y hay lugar, lugar para todos nosotros". Está de más decir que su ilusión quedará frustrada. Si los amigos contestan, lo harán con circunloquios, con evasivas. Definitivamente, no están dispuestos a abandonar la vida, cómoda o no, que llevan en Inglaterra, para lanzarse a esa imprevisible aventura que solo podía tener cabida en la mente afiebrada del joven Lawrence. Incluso, entre el primero y el segundo viaje a México, volvió unos meses a Londres y, allí, un buen día, decidió invitar a varios amigos a comer en el Café Royal. Al final de la comida, les pidió abiertamente que se fueran con él y con Frieda a México para fundar entre todos la colonia. La idea, sin embargo, no fue secundada por ninguno de ellos, excepto por Dorothy Brett que, ocho días después, se embarcaría con Lawrence y Frieda en el Aquitania rumbo a México. "¿Cuántos creyeron en la filosofía lawrenciana? ¿Cuántos se sentían suficientemente fuertes como para confiar en ella - y en los estados de ánimo del Profeta—, como para seguirlo ciegamente en sus pasos por el mundo hacia la Tierra Prometida?" - se pregunta Jorge Ruffinelli, y concluye: "Una cosa era sońar con el Ideal, sabiendo que ese Ideal estaba allí para ser sońado. Otra, intentar como quijotes increíblemente ingenuos la aventura imposible" (Ruffinelli: 87 ). 
El desinterés o la indiferencia de los amigos, sin embargo, no arredra a Lawrence, tampoco lo desilusiona. Se instalará, con Frieda y Dorothy, a orillas del lago de Chapala, y allí dará rienda suelta a su imaginación: se entregará febrilmente a un nuevo proyecto literario, esa novela $-\mathrm{La}$ serpiente emplumada - que debía dar cuenta de su experiencia mexicana.

Son muchos los comentarios críticos, y casi todos en el mismo sentido, que despertó la decisión del escritor inglés de instalarse en nuestro país y tratar de comprenderlo a través de esa larga y alucinante novela, de la que, a los pocos meses, tendría ya una primera versión, un primer borrador. La mayor parte de esos comentarios coinciden en señalar que lo que Lawrence vino a buscar en México no fue sino una suerte de proyección de sí mismo, de sus ideas mesiánicas, de su irracionalismo, de la fuerza del instinto sobre la inteligencia, de su acendrado misticismo. México fue, para Lawrence — según Ruffinelli—, el lugar ideal "para expresar sus ideas redentoras, para dejar salir de sí un poco de la violencia que llevaba adentro, para diseñar lo que consideraba el surgimiento del 'hombre nuevo' en el Nuevo Mundo' (71).

Y Emmanuel Carballo, por su parte, y de una manera un poco más incisiva, señala:

México [...] solo fue en la vida y la obra de Lawrence un pretexto de evasión y búsqueda. Sus tres viajes a México (comprendidos entre 1923 y 1925) pueden catalogarse como simples excusas que un hombre iluminado se da a sí mismo para buscar en un país, que él considera primitivo, argumentos que comprueben sus tesis acerca del triunfo de la sangre sobre la razón, de los instintos sobre la inteligencia y del sexo sobre la enajenación. Lawrence viajó a México con un solo propósito, el de encontrar aquí el paraíso perdido, y como no pudo encontrarlo se dejó ganar por la exasperación y el odio, aunque también, ante ciertos hechos y personas, por el amor y la ternura (15).

Los críticos por lo general coinciden con esta idea de que Lawrence, y no solo él sino también otros viajeros europeos, vinieron a México interesados no en lo que era el país, en lo que ocurría en estas tierras desoladas al otro lado del océano, sino a encontrarse exclusivamente a sí mismos, a lo que ya traían en las maletas, a realizar aquí un sueño esencialmente europeo. México sería, a lo sumo, un telón de fondo, con sus montañas, con sus lagos, con sus indios, con sus plantas de maguey, que les permitiría poner en práctica todas las fantasías que el 
viejo continente rechazaba. No dudo que haya una buena parte de verdad en esas críticas, pero me parece que, en el caso de Lawrence, hubo al menos algún intento, aunque fallido, por entender lo que ocurría a su alrededor, esa realidad convulsa y violenta que vivía México en esos años, y que no se entregaba fácilmente a la comprensión dentro de los parámetros metódicos y ordenados de la mentalidad occidental. Y es cierto, como señala Carballo, que los comentarios de Lawrence sobre la nueva realidad que tenía ante los ojos estuvieron marcados por esa contradicción en la que se conjugan "la exasperación y el odio", "el amor y la ternura”, es decir: los extremos más opuestos e irreconciliables.

Ronald G. Walker, en un libro sobre los escritores ingleses en México y que devela en el título precisamente esa contradicción: Paraíso infernal, señala: "los escritores extranjeros [que visitaron el país durante esos años] no pudieron entregarse al sueño mexicano sin que este se transformara ante sus ojos, tarde o temprano, en pesadilla. Y en el centro de esta pesadilla yace, para el extranjero, el espectro de la muerte violenta" (29). Y, un poco más adelante, desarrolla el comentario:

México es presentado como una tierra saturada de muerte: la política, el arte, las fiestas y las demás costumbres sociales, los rituales religiosos antiguos y modernos, el paisaje mismo: todo esto se siente como una manifestación de una subyacente, endémica fijación con la muerte en México [...] Vieron el movimiento [revolucionario] y sus excesos violentos como parte de los múltiples episodios sanguinarios del pasado de México, [...] una manifestación del carácter mexicano esencial (33).

Las primeras impresiones de Lawrence y Frieda sobre nuestro país no hacen sino confirmar el comentario de Walker, dirigido no solo a ellos, sino a todos los escritores ingleses que visitaron México durante la primera mitad del siglo xx. Durante su primer viaje, en 1923, Lawrence recorre la costa occidental del país acompañado por su amigo Witter Bynner, con el que, a lo largo del viaje, sostiene una intensa conversación sobre sus impresiones cotidianas, que más tarde Bynner recogerá en su libro Journey with Genius. Una de ellas se refiere precisamente a la crueldad del mexicano, a una violencia que está inscrita en su historia y que parece que emanara de la propia tierra que pisa: "lo que hicieron los aztecas, lo que hizo Cortés, lo que Díaz hizo: una crueldad total, sin 
fin. La tierra misma se lo hace a quien viva en ella. [...] Es una tierra de muerte" (31).

Aunque lo que completa y contextualiza el comentario de Lawrence sobre la violencia del mexicano, ya no como una violencia inscrita en su historia sino en su esencia, es la observación de Frieda, durante ese mismo viaje, cuando visitan el cuadrángulo de Quetzalcóatl en Teotihuacán:

Entonces tuve un atisbo del viejo México, los antiguos sacrificados; corazones, aún palpitantes, alzados al sol, para que el sol bebiera su sangre. Allí había ocurrido todo. [...] Temor de esa gente a la que no le importa matar y no le importa morir. [...] La muerte y los sacrificios y los dioses crueles parecían reinar en México bajo la luz del sol y bajo el esplendor de las flores y de múltiples aves y blancos picos volcánicos (140).

Violencia, crueldad, muerte son conceptos centrales en la imagen que Lawrence nos ha dejado de México y el mexicano, no solo a través de sus cartas y sus conversaciones con Bynner, sino también y sobre todo en su propia obra de ficción: Mañanas en México y La serpiente emplumada. Refiriéndose a esta novela, Drewey Wayne Gunn ha señalado: “Todos los mexicanos parecen prisioneros de una violencia sin causa o sumergidos en un letargo inútil. La muerte rumia sobre esa tierra; no el horrible pero significativo ritual del sacrificio azteca, sino la muerte andrajosa, macilenta, vulgar, sin siquiera la pasión de su propio misterio" (161).

Y, en realidad, ya desde la primera escena de La serpiente emplumada la crueldad del mexicano salta a la vista del lector. La novela inicia con la descripción de una corrida de toros. No se trata, por supuesto, de una fiesta popular mexicana. La fiesta de toros es esencialmente española, pero México ha sabido incorporarla a sus tradiciones populares, con un toque propio, hasta hacerla plenamente suya. Una de las primeras cosas que hacen los Lawrence al llegar a la ciudad de México es asistir a una corrida de toros. No saben lo que van a encontrar allí, pero vienen decididos a conocer el país en sus más profundas raíces populares. Y la impresión que esa fiesta les produce es tan fuerte que el viajero inglés decide abrir su novela precisamente con esa imagen en la que se aúnan la crueldad y el entusiasmo, la fascinación y el asco.

Owen, Kate y Villiers han comprado localidades de sol, no solo porque "querían economizar", sino sobre todo porque "preferían estar en- 
tre la multitud" (Lawrence 1940: 9). La sensación de Kate, al entrar a la plaza y dejarse conducir hasta sus asientos, es contundente: "Kate tuvo la impresión de hallarse metida en una trampa para cucarachas" (11).

Antes del inicio de la fiesta, antes del enfrentamiento del toro y el torero, en las graderías ha comenzado la algarabía del pueblo. El juego consiste en quitarse unos a otros el sombrero, que debía protegerlos del sol, y lanzarlo a la multitud alborozada:

—Mira, mira cómo se divierten — comenta Owen.

— [...] No me gusta nada — dice Kate, incómoda en medio de la alegría popular-. Me molesta la gente ordinaria.

[...]

—Es el juego — repuso Owen convencido (12).

Pero no se trataba solo de sombreros volando en el aire; a los sombreros siguieron las naranjas, las cáscaras de plátano, que venían a estrellarse contra las cabezas de Owen y Villiers. “¡Cómo los detesto!” (13), exclamó de pronto Kate.

Varias bandas de música entran en ese momento en la plaza y el griterío del populacho exaltado no se hace esperar: “iMúsica! ¡Música!” "El clamor llegó a ser un alarido salvaje" — comenta Lawrence-, "propio del populacho degenerado de México" (14). Y, de pronto, como si se rompiera un dique, la multitud irrumpe en la zona numerada de sol apropiándose de asientos mucho más caros por los que no habían pagado, y los tres amigos, pasando del asombro inicial a un miedo repentino, se ven rodeados por la algarabía grosera de la multitud. Dos mexicanos gordos y mal vestidos se sientan delante de Owen y Villiers impidiéndoles la vista de la plaza. Villiers protesta y logra librarse de uno de ellos. Owen se limitó a reflexionar en silencio: "Existen infinitos complejos de inferioridad y el mexicano de las ciudades tiene uno marcadísimo que le hace ser extraordinariamente agresivo una vez que se le provoca" (16). Owen decide, entonces, no provocarlo: se limitó a sonreír inquieto, dejando que el mexicano "se apoyara en él como en el respaldo de un sillón" (17).

Aparecen al fin los toreros desfilando por el centro del ruedo, saludando con un gesto al palco oficial y a la multitud enardecida. "Con sus prominentes posaderas, sus coletas y sus rostros afeitados, los famosos toreros tenían un aspecto de eunucos o de mujeres disfrazadas. [...] 
¿Eran aquellos tipos los ídolos de la multitud, los valientes toreros? — se pregunta Kate- . [...] Más bien parecían ayudantes de carniceros [...], mujeres que se dedicasen a esa tarea" (17-18).

No es necesario describir aquí detalladamente la corrida de toros que los tres anglosajones contemplan marcados por la aversión y el espanto. Todo el que haya asistido alguna vez a una corrida de toros ( $\mathrm{y}$ aun el que no ha asistido) sabe de sobra en qué consiste esa fiesta de crueldad y de sangre que exalta hasta el delirio el entusiasmo del espectador habitual. Para Kate, en cambio, la sorpresa inicial deviene enseguida rechazo, repulsión:

En su vida sintió Kate una sorpresa mayor. En el fondo de su alma había creído que iba a asistir a un espectáculo de valor, y antes de darse cuenta de nada se encontraba ante un animal herido que revolvía con sus cuernos en el vientre de un caballo anciano y débil que agitaba con esfuerzo las patas.

La impresión estuvo a punto de vencerla [...]: la cobardía humana, la bestialidad, el olor de la sangre, el hedor repugnante de los intestinos destrozados [del caballo]. Volvió la cabeza a otro lado (19).

La multitud exaltada daba alaridos de entusiasmo, de alegría desbordante, mientras Kate, fuera de sí, accedía al límite del horror y del asco. "Yo me voy" (22), le dijo a Owen, poniéndose de pie. Owen, sin moverse de su asiento, la vio dirigirse a la salida de la plaza.

Ya en la puerta, mientras esperaba el taxi que debía devolverla sana y salva a su hotel, Kate tiene todavía un instante para reflexionar sobre el espectáculo que acababa de presenciar: "Lo que más le repelía [...] era la fealdad de todo aquello. Conocía muchas ciudades de todo el mundo, pero México tenía una fealdad interior, repugnante" (24).

La escena de la plaza de toros y la reacción de Kate no solo le ha servido a Lawrence para poner en marcha el discurso de su novela, sino, sobre todo, para dejar allí, ya desde las primeras páginas y con toda la fuerza de su escritura, una primera imagen de México y del mexicano que irá acentuándose a lo largo de todo el libro (y más tarde también en Mañanas en México). Una imagen que, a través de los adjetivos que la constituyen, desde la visión de Kate, no hará sino calificar (o, más bien, descalificar) los comportamientos de un pueblo y de una nación entera. "Crueldad", "asco", "ordinariez", "barbarie", "inferioridad", "mie- 
do", "agresividad", "repulsión", "cobardía", "horror", "fealdad interior", "repugnancia", son algunos de los calificativos en los que ha quedado atrapada la imagen de México y del mexicano. Y todo ello a partir únicamente de la descripción de una sencilla fiesta popular.

Me parece que en las reflexiones de Lawrence sobre nuestro país, más que un intento por comprender lo que le rodea, hay una suerte de movimiento defensivo, un intento de ponerse a resguardo de toda una serie de conductas y comportamientos que manifiestan, ante los ojos del europeo, una diferencia, pero no la diferencia idealizada y mistificada que el europeo espera, sino una diferencia que aparece ante sus ojos como fealdad.

Como ya dijimos, Lawrence llega a México seguro de que va a encontrar aquí el lugar perfecto para realizar su utopía: un rancho, junto al lago de Chapala, donde él y sus amigos podrán vivir plenamente una vida libre en todos los sentidos, al margen de las exigencias (políticas, ideológicas, morales, etc.) de la civilización occidental. ¿Por qué México? Porque precisamente por su diferencia (y a pesar de su fealdad) "en México hay algo saludable, conveniente, algo que reabre, por lo menos parcialmente, las compuertas del alma", le escribe a Adele Seltzer (citado por Parmenter: 37), la esposa de su editor neoyorquino, durante su primer viaje a México. Es una idea que, durante esos meses, reitera de una carta a otra. Unos días después, le escribe a Frieda, que había regresado a pasar el invierno en Inglaterra: "México sigue siendo muy atractivo. Es un excelente lugar para vivir. No está 'domado" (37). Y ese mismo día, en una carta a la baronesa Anna von Richthofen, madre de Frieda, lo reitera: "Me gusta este país. Esta nación morena me regala fortaleza, aunque no sé cómo. Está pletórica de reciedumbre masculina" (37). Y el 20 de noviembre de 1923, en una carta a Mabel Dodge Luhan, su amiga norteamericana, insiste: "Tengo la sensación de pertenecer aquí. [...] Aquí está la fuente indígena” (37).

En eso radica la diferencia: México no es un país "domado" por las blandas convenciones europeas, es una "nación morena", "pletórica de reciedumbre masculina", "saludable" porque "reabre las compuertas del alma", porque "aquí está la fuente indígena". Figuras retóricas del discurso lawrenciano en las que México no aparece realmente como es, sino como el observador inglés necesita que sea. Y lo necesita no solo para justificar su viaje y su decisión de quedarse aquí, sino porque, de lo contrario, se quedaría sin tierra bajo los pies. No solo ha abandonado 
Europa, sino también Australia y Estados Unidos, ¿adónde ir, entonces, si México, su "fuente indígena", no le "reabriera las compuertas del alma", si la escueta y fría realidad mexicana se le mostrara tal cual ante los ojos y lo defraudara? Su necesidad es, sin duda, apremiante, como también lo es su acuciante idealización.

La visión de México que nos ha dejado Lawrence oscila entonces en un doble movimiento: aquiescencia, idealización, necesidad de pertenencia, pero también: confusión, rechazo, extrańamiento, repugnancia. En los dos casos, el resultado que se impone es la figura de la incomprensión precisamente en el mismo movimiento que trata de comprender. Y es que los ojos que contemplan la realidad mexicana que los rodea no logran desprenderse de las telarańas europeas que los cubren.

Durante el primer viaje de los Lawrence a México, el país está atravesando por un momento de fuerte agitación revolucionaria. El 7 de diciembre de 1923, en Veracruz, estalló el levantamiento de Adolfo de la Huerta contra Calles, dos facciones revolucionarias que se disputaban mutuamente el poder. De la Huerta consideraba que Calles, apoyado por Obregón, le había usurpado la presidencia, y el único camino que le quedaba para devolver las cosas a su justo lugar era el levantamiento armado. La insurrección huertista fue sofocada en junio de 1924, pero aquellos meses marcaron al país con una verdadera guerra civil, que se prolongaría aún con el intento de levantamiento de Ángel Flores, exgobernador de Sinaloa que, aunque no había participado en la insurrección de De la Huerta, era un fuerte opositor de Obregón y Calles.

D. H. Lawrence presencia toda esa efervescencia a su alrededor sin llegar nunca a comprender lo que ocurre ante sus ojos. En una carta a su amigo Middleton Murry, del 15 de noviembre de 1923, escribe:

Todo es muy inseguro, y en verdad muy confuso. Los indios son pequeńos salvajes extrańos, y malévolos agitadores los bombardean con trocitos de socialismo, haciendo que todo sea un enredo. No es exageración: hay una especie de caos. Supongo que la intervención de Estados Unidos es inevitable. Lo sabes: el socialismo es un fracaso. Hace de la gente una masa blanda, y especialmente de los salvajes. Y 70 por ciento de esta gente son verdaderos salvajes, más o menos como lo eran hace 300 años. La población hispanomexicana se pudre sobre el salvaje populacho negro. Y aquí el socialismo es la farsa de farsas, pero es muy peligroso (53). 
Aparte de su calificación del socialismo como una "farsa peligrosa", como un "fracaso" (opinión a la que el autor tiene plenos derechos y que no tengo por qué discutir aquí), lo que me interesa resaltar es la incapacidad de Lawrence para entender (y explicarse) el momento de convulsión política por la que atraviesa el país durante esos meses. En lugar de inquirir las razones de ese proceso, por elementales y contingentes que fueran, prefiere calificarlo por sus efectos: "inseguridad", "confusión", "caos". Y aunque la función de un adjetivo en un enunciado consiste en precisar o determinar a un concepto, en algunos casos, como en este, actúa, más bien, para enrarecerlo, para hacer aún más difícil su comprensión. Además de resultar tautológicos (pues toda convulsión revolucionaria conlleva necesariamente inseguridad, caos, confusión), estos calificativos, en lugar de esclarecer, contribuyen a la incomprensión de lo que señalan. Y lo mismo ocurre al definir al indio mexicano como "salvaje": todas las contradicciones y complejidad que caben en ese sujeto son opacadas a través de ese adjetivo reductor: "salvaje". No hay necesidad de explicar más; una sola palabra lo dice todo. ${ }^{1}$

Se trata de una operación constante (aunque no la única) en la obra de D. H. Lawrence sobre México. Y que ha llevado a algunos de sus críticos, concretamente a Jorge Ruffinelli y a Drewey Wayne Gunn, a hablar de "mesianismo", "irracionalidad", "racismo" e incluso una cierta tendencia "fascista" en el pensamiento lawrenciano. El crítico norteamericano señala explícitamente: "esa fe en el destino individual de cada persona acercó fatalmente a Lawrence al fascismo. Esta idea general hizo al libro [La serpiente emplumada] popular en los círculos fascistas; incluso se convirtió en modelo de un grupo británico" (165). Ross Parmenter y Eloy Urroz (25), en cambio, no están de acuerdo con esta fácil descalificación del escritor inglés. Ross Parmenter concretamente señala: "Lawrence era teocrático, pero teocrático ingenuo y su fe en los 'aristócratas naturales' lo hacía ciego a los peligros de confiarles un poder arbitrario. [...] Pero no era fascista. Denunció el fascismo en St. Mawr, que escribió después de la primera versión de La serpiente emplumada y antes de la segunda" (360). Habría que tener en cuenta que en los

\footnotetext{
${ }^{1}$ En este sentido, Jorge Ruffinelli ha señalado: "El rechazo de cierta barbarie [... y yu incomprensión de lo que pasaba en México en términos políticos, lo hacían negar a un país que no tenía con él aspectos comunes en el orden cultural, y solo le había dado pábulo para desarrollar sus ideas sobre la necesidad de la reivindicación del hombre mediante la sexualidad, la liberación irracional del instinto y el autoritarismo político" (82-83).
} 
ańos en que Lawrence escribe La serpiente emplumada el pensamiento europeo está todavía fuertemente influido por la ideología colonialista que dominó a todo el siglo XIX y se extendió al menos hasta fines de la Segunda Guerra Mundial. Si Joseph Conrad (El corazón de las tinieblas) da cuenta del peso de esta ideología en el siglo Xxi, Ezra Pound, con su abierta filiación a las ideas fascistas italianas, lo hace también en la primera mitad del siglo xx. Sin embargo, el caso del escritor inglés es diferente. Coincido con Urroz y Parmenter: me parece que hablar de fascismo, al referirse a las ideas de Lawrence, resulta un poco excesivo. No es la ideología de Mussolini ni del nacionalsocialismo ${ }^{2}$ las que configuran el pensamiento aristocratizante y teocrático del escritor inglés, incluso en la carta a la baronesa Anna von Richtofen citada hace un momento, Lawrence rechaza abiertamente tanto al bolchevismo como al fascismo (Moore, ed.: 741). Los otros epítetos, en cambio - racismo, irracionalismo, mesianismo-, sí quedan plenamente justificados a través de la lectura de su obra sobre México.

En Mañanas en México, el pequeño libro de relatos que Lawrence escribió durante su breve estancia en Oaxaca, da plena cuenta de ello. Sentado en el jardín de su casa, en pleno diciembre, se asombra del clima, "ni muy fresco ni muy cálido", y del crisol insólito de formas, aromas y colores que lo rodean: la enorme variedad de flores y de plantas, los pájaros que revolotean entre las ramas de los árboles, el canto de los gallos, el parloteo de los loros, el viento suave que mezcla el olor de las flores, el ocote y los cafetales. La constatación de toda esa voluptuosidad de formas y colores que estallan a su alrededor hace que el narrador se pregunte si toda esa feracidad responde a la teoría de la evolución, "como una cinta atada a la primera causa". Y enseguida se decide en favor de la teoría de los mundos sucesivos o de los cinco soles de los antiguos aztecas:

Me satisface más la teoría de los aztecas acerca de los Soles, es decir, una serie de mundos sucesivamente creados y destruidos. El sol, de repente, entra en convulsiones, y los mundos se apagan del mismo modo que otras tantas velas cuando alguien tose en medio de ellas. Después, sutil y misteriosamente, el sol vuelve a estremecerse y una serie nueva de mundos parpadeantes comienza a iluminarse (Lawrence 1942: 13).

\footnotetext{
${ }^{2}$ D. H. Lawrence muere tres años antes de que Hitler subiera al poder en Alemania.
} 
Así, toda esa pluralidad de formas y colores no manifiesta una continuidad causal de unos a otros, sino una simultaneidad inconsecuente, una contigüidad sin causa ni efecto. Se trata, más bien, de un estallido de figuras que se devora y resurge a cada instante sin solución de continuidad alguna.

En este relato, "Corasmín y los loros", Lawrence explica brevemente la teoría de los cinco soles de los aztecas: cada sol implica un orden del mundo dominado por una especie determinada de animales (insectos, peces, aves, mamíferos, reptiles, etc.) que a la muerte de un sol será destronada por otra aunque sin desaparecer por completo de la tierra; lo que desaparece es solo su función dominante. El hombre nace con el quinto sol, que surgió de las aguas. Y todos los animales que lo rodean (el perro, el elefante, el cocodrilo, la serpiente, el águila, el mono) se sorprenden y se someten ante el poder de la palabra de esa nueva especie superior que es el hombre. Es sintomático que Lawrence aproveche aquí para negar una vez más la teoría de la evolución al rechazar toda relación de continuidad entre el mono y el hombre. Reconoce que el mono es "la más lista de las criaturas" hasta la aparición del hombre, pero enseguida afirma enfáticamente que "no existe ningún lazo de evolución que lo una a nosotros, como un cordón umbilical. ¡No! Entre él y nosotros hay todo un cataclismo y otra dimensión" (18).

Aunque el verdadero giro del cuento se produce cuando este juego de discontinuidades entre el mono y el hombre se establece de pronto, sorpresivamente, entre el narrador europeo del cuento y Rosalino, el mozo indígena que lo atiende en el jardín de la casa. "Tampoco nosotros nos pondremos de acuerdo. [...] Entre nosotros existe el mar de la otra dimensión" (20). E inmediatamente se lanza a establecer correlaciones entre él, Rosalino y el loro que convierten al indio mexicano en una especie muy inferior en relación con el hombre europeo, como el loro lo es en relación al indio: "Puede [Rosalino] imitarme, aún más de lo que soy. Como el loro a él. Y tengo que reírme de $m i$, un poquito forzadamente, de igual manera que él enseña los dientes cuando sorprendo sus ojos en el momento que el loro imita su silbido. Con una mueca, con una sonrisa helada pagamos nuestro tributo a la otra dimensión" (20). El indio es al hombre lo que el loro es al indio: una especie inferior. Y entre los dos se abre una dimensión de absoluta incomunicación. Así, con este giro del relato, Lawrence da paso, una vez más, a la expresión de ese fuerte sentimiento aristocratizante y racista 
que, aunque ya existía en él antes de venir a México, terminó acendrándose y consolidándose aquí a través del asiduo contacto con los indios y mestizos mexicanos a los que siempre consideró una raza muy inferior a la europea.

En otros dos relatos, "Paseo a Huayapa” y "El mozo" (en realidad, no se trata de relatos distintos, sino de distintas imágenes de un mismo relato), el escritor inglés se ocupa de dos conceptos que resultan esenciales para distinguir barbarie y civilización: las nociones de espacio y tiempo. Y de nuevo, a través de ellas, establece el abismo que separa al indígena del europeo. Al entrar a Huayapa, el narrador se siente desorientado. Todo le resulta caótico allí, sin orden alguno: laberinto de calles, cercas de cactus, negras chozas de adobe todas iguales. "La sensación de desorientación es intensa, en medio de esas estúpidas y repelentes cercas de cactos" (32). Solo el contacto con la presencia de la civilización europea lo devuelve de pronto a una cierta noción de orden, de orientación, de sentido, en medio del caos indígena.

Si no hubiera iglesias para marcar un punto determinado en estos villorrios, no habría manera de orientarse. [...] Los españoles, sin embargo, en medio de estas negras chozas de adobe, tuvieron inevitablemente que levantar la blanca magnificencia de una grande, solitaria y perdida iglesia de dos torres; $y$ en donde hay una iglesia, hay forzosamente una plaza. Y una plaza es un Zócalo, un centro, un eje (32).

El nuevo símil con el que remata esta primera impresión de Huayapa habla por sí mismo en cuanto a la concepción que Lawrence tiene del mundo indígena: "La iglesia mayor se encuentra en un estado casi de miseria, en un abandono desesperante, a la manera de un gran hombre blanco en harapos, cautivo en un mundo de hormigas" (33). Una vez más esa escala racial que hace del discurso del escritor inglés un discurso francamente racista: ese "gran hombre blanco" (no importa que esté en harapos) es la posibilidad de orden y racionalidad, de orientación y sentido, en ese oscuro mundo caótico de hormigas nativas que lo acorrala. La propia descripción de los habitantes de Huayapa redunda en la idea de que el indígena no rebasa la condición de insecto: "en enjambre, todos los pequeñitos hombres del pueblo, con sus vestimentas de manta blanca y sus anchos sombreros [...], se agitan y mueven como insectos vestidos de blanco" (33). 
Si el espacio en el que vive el indio mexicano es confuso, caótico, sin puntos de referencia, ininteligible, algo similar ocurre con su noción del tiempo: "para el indio" — - señala Lawrence_-, "el tiempo es una vaga y confusa realidad. Hay solo tres tiempos: en la mañana, en la tarde, en la noche. Ni siquiera el mediodía, ni el anochecer" (49). Y más adelante, puntualiza: "Limpio, limpio, limpio del pasado y del futuro; dejar limpio el momento del presente, sin complicaciones; dejar únicamente el momento, rígido y agudo y sin conciencia, como el puñal de obsidiana” (51).

Si el hombre, como pensaba Ortega y Gasset (645-663), se define fundamentalmente por habitar en el tiempo, en la historia que él mismo construye, por poseer una memoria que lo liga al pasado y una esperanza que lo guía hacia el futuro, el indio, entonces, de acuerdo con las observaciones del viajero inglés, no cabe definitivamente en esa categoría. Su vocación por el presente, ese instante fuera del tiempo, ${ }^{3}$ sin complicaciones, sin preocupaciones, sin conciencia, lo coloca más cerca del animal que del hombre. El tiempo es una categoría esencialmente humana; allí, los actos del hombre construyen una continuidad en la que se reconoce, una historia; el animal, en cambio, es ajeno al tiempo, carece de historia, no deja más vestigios de su existencia que sus propios huesos. Es a ese estado de naturaleza, sin tiempo, sin racionalidad, sin memoria, sin espíritu, al que, según Lawrence, pertenece el indio mexicano. E inmediatamente, a partir de esta doble carencia espacio-temporal, establece una jerarquía racial que divide al mundo entre señores y siervos: "Mas el gran mono blanco [el europeo] tiene las llaves del universo, y el mexicano de ojos negros tiene que servirle, a fin de poder subsistir" (1942: 51). Como ahora el mozo Rosalino le sirve a él.

Abolir la continuidad causal del tiempo es abolir también al pensamiento, pues el pensamiento — su racionalidad, su discurso- ocurre en el tiempo, requiere al tiempo para desarrollarse, y su funcionamiento consiste precisamente en establecer relaciones de causa y efecto entre unos fenómenos y otros, como lo hace la propia lógica del lenguaje, condición indispensable para distinguir la cultura de la barbarie. Por lo tanto, negar la continuidad del tiempo es negar la condición de

\footnotetext{
3 "El instante es al tiempo lo que el punto al espacio", diría Henri Bergson (116131).
} 
pensar, sin duda el acto humano por excelencia. $\mathrm{Y}$ es justo esto lo que caracteriza a los indios, según el viajero inglés: "el momento es incambiable como el cuchillo de obsidiana, y el corazón del indio es cortante como el momento que divide el pasado del futuro y sacrifica a ambos" (54).

Así, la escisión entre el hombre blanco y el indio, según Lawrence, es total y absoluta; es sobre todo irreconciliable, pues no nace solo del color de la piel, de costumbres y comportamientos distintos, de lenguas diferentes, sino de algo mucho más esencial, que no admite ninguna solución de continuidad: se trata del funcionamiento de la conciencia; es decir, de la manera de entender y vivir el mundo. Y allí, entre la conciencia del europeo y la del indígena, no hay ninguna vía de comunicación, son sencillamente intraducibles: "Los modos de la conciencia de los indios son diferentes y fatales a los de la nuestra. [...] Los dos modos, las dos corrientes nunca se encontrarán. Ni siquiera podrán reconciliarse. No hay ningún puente, ninguna conexión" (87). Y termina extendiendo esta condición de incomprensión, de incomunicabilidad, a la relación del hombre occidental con cualquier otra cultura que no sea la suya: "la misma paradoja existe entre la conciencia del hombre blanco y la del hindú, polinesio, o habitante de Bantu. Es la eterna paradoja de la conciencia humana" (87-88).

En La serpiente emplumada, en cambio, aunque se mantiene este acendrado racismo en Lawrence, la conclusión resulta muy diferente. Ese racismo deviene, inesperadamente, una suerte de mesianismo, de redención. Y las dos razas opuestas y enfrentadas terminan encontrando vías de contacto, de comunión.

En esta novela, la imagen que se proyecta del país y de sus habitantes está marcada por un sentimiento de miedo, de terror, que desencadena, en el europeo que permanece aquí, la sensación de que vive cada día y cada noche en la ciudad bajo su propio riesgo, que lo que lo rodea no es más que una amenaza constante. Kate ha regresado al hotel, después de esa tarde de domingo en la plaza de toros. Es de noche e intenta, sola en su habitación, conciliar el sueño. Pero no puede dormir. En mitad del insomnio, su mente divaga sin cesar y por un momento parece inevitable que su pensamiento vuelva a centrarse en la ciudad de México que, del otro lado de la ventana, se hunde en el silencio de la noche, como un abismo del que emana un tufo a un peligro incomunicable: 
La pasó oyendo los ruidos de la ciudad de México; luego el silencio y esa especie de temor vago que suele emanar de la oscuridad de una noche mexicana. En el fondo de su alma odiaba a México: hasta tenía miedo. En pleno día la ciudad tenía un encanto especial, pero por la noche salía a la superficie toda su bajeza y todo su mal (1940: 33).

Y unas páginas más adelante termina remitiendo esa sensación de amenaza y temor que la ciudad y su noche producen en el europeo al pasado remoto de México, a la presencia incesante de la muerte que, desde los antiguos sacrificios de los aztecas, ha flotado sobre el país como una sombra siniestra, macabra:

Kate comprendía perfectamente lo que le dijo un mexicano: El grito del mexicano es siempre el grito del odio. Como opinaba Don Ramón, las famosas revoluciones de México empezaban con ; Viva! Y acaban siempre con ;Muera! Muera éste, muera el otro, [...] siempre muerte, muerte, muerte, grito repetido e insistente como los sacrificios aztecas: algo siniestro y macabro.

[...] En otros tiempos en México se celebraban ritos de muerte. Ahora era la muerte descarnada, pingajosa, escuálida, vulgar, sin la pasión de su propio misterio (54).

Si la presencia de la muerte que percibe Kate emanando de la noche mexicana ha perdido el misterio de su origen sagrado, ha perdido entonces toda justificación posible, todo sentido. En su origen, la muerte daba significación a la vida, le daba un valor, una consistencia metafísica: era el punto de comunicación entre los hombres y los dioses, entre los hombres y el cosmos; era el instante de renovación de la vida misma, la posibilidad de su continuidad. Hoy, al haber abandonado su carácter sacro, la muerte permanece allí, sobre la ciudad, recorriendo de un extremo al otro todo el país, pero como una presencia in-significante, ya no le dice nada a nadie, tan solo está ahí — "descarnada”, "pingajosa”, "escuálida”, "vulgar" — para producir ese miedo, ese terror irracional que nace de la pérdida de sentido, de la ausencia de significación.

$\mathrm{Y}$ es a partir de esa ausencia de sentido que desvaloriza la vida, que Lawrence salta a establecer nuevos símiles que asemejan a los mexicanos con los animales, con los insectos: sucios, peligrosos, repugnantes. Seres "no creados" o "a medio crear", en cuyos rostros anidan los signos del mal: 
Los hombres:

También debía recordar la gran cantidad de individuos pequeños, con aspecto insignificante muchas veces, algunos con costras de suciedad, que miraban con hostilidad seca y fría y que andaban con pasos silenciosos, como si fueran gatos. Individuos venenosos, flacos, fríos, parecidos a escorpiones y tan peligrosos como ellos.

Y las caras verdaderamente terribles de algunos tipos de la ciudad, tumefactas a causa del veneno del tequila y con los ojos un poco vidriosos y como si mirasen a través de un velo de maldad. En ninguna parte había encontrado rostros en los que se pintase el mal con tanta claridad como los que se veían en México.

\section{Las mujeres:}

Las mujeres eran también lo mismo. Con sus largas faldas y los pies descalzos, el gran chal oscuro que se llamaba rebozo a la cabeza y ajustado a los hombros, hacían el efecto de ser la imagen de la sumisión salvaje y de encarnar esa feminidad primitiva del mundo tan conmovedora y tan lejos de nosotros. [...] El espectáculo de una de esas iglesias llenas de mujeres humilladas implorando alguna gracia, acurrucadas como seres no creados, le causaba a Kate repugnancia y al mismo tiempo cierta ternura.

Tenían el pelo negro y mal peinado, casi siempre lleno de liendres; solían llevar a los chiquillos colgados como una calabaza en el chal terciado en los hombros, los pies y piernas siempre sucios, y se movían con ondulación de reptil bajo las largas faldas de algodón, también sucias. Y los ojos oscuros de los seres a medio crear, dulces suplicantes pero con un vislumbre de insolencia. Y una especie de temor de no ser capaces de llegar a la completa creación, unido a la inevitable agresividad contra lo elevado, cualidad característica de la serpiente (83-84).

Si en estas líneas el hombre mexicano termina reducido a unos cuantos rasgos en los que se configura la imagen del veneno y del mal y cuyo referente es el escorpión, la mujer mexicana es caracterizada a través de la figura de la sumisión y la suciedad y es remitida a otro animal que repta en la inmundicia: el reptil, la serpiente. Pero lo que definitivamente hay que resaltar aquí es que la posibilidad de establecer esas similitudes y esas correspondencias proviene de una serie de características raciales - la estatura: "individuos pequeños"; el color del pelo o de los ojos: "negros", 
"oscuros" - que convierten a la raza indígena (también al mestizo) en una raza "a medio crear", "incapaz de llegar a la completa creación”, muy por debajo de los mínimos requisitos para poder considerarla humana.

Ya no se trata aquí de determinaciones sueltas, independientes unas de otras, para significar a un país y a sus habitantes; esas determinaciones comienzan ahora a conformar un cuerpo de conceptos en el que la imagen de México y su gente ha quedado atrapada: muerte sin significación; miedo irracional; desvalorización de la vida; odio generalizado; sujetos a medio crear, más cercanos al animal o al insecto que al hombre, en los que anida la semilla del mal. Y todo ello lleva a una afirmación contundente que separa al hombre mexicano del resto de la especie humana: en México es imposible ser un ser humano, como le dijo un profesor universitario a Kate cuando visitó los murales de Diego Rivera en la Universidad de México. El corte se ha producido al fin: no hay continuidad alguna entre el mexicano y los demás hombres, entre México y el resto del mundo. Aquí, entonces, puede ocurrir cualquier cosa: cualquier aberración, cualquier milagro. Es una tierra de muerte, pero quizá también de resurrección para la humanidad entera, porque ese hombre no creado, que es el mexicano, puede quizá alcanzar al fin la creación completa, configurando un hombre distinto a todo lo conocido, un "hombre nuevo". México es, entonces, un enigma que habría que desentrañar. Y Lawrence se entrega enseguida, más que a desentrañar el enigma, a bordar a través de él su sueño mesiánico, su utopía imposible.

El mesianismo de Lawrence parte de la idea de que el hombre europeo se encuentra exhausto, ha agotado las fuerzas vitales que en algún momento habrían podido llevarlo a su renovación; su fría racionalidad, su cientificismo a ultranza, su sometimiento a la técnica y a la noción de progreso han hecho de él un hombre débil, sin vida interior, sin espiritualidad, sin vocación de cambio, condiciones imprescindibles para esa transformación de la humanidad que él considera tan necesaria hoy y a la que ha decidido darle voz, convirtiéndose en su vocero universal. Si no es en Europa, debe ser en América, en México concretamente, donde encuentre esa fuerza vital que produzca el cambio, la necesaria transformación del hombre hacia horizontes espirituales más limpios, más puros, desasidos de la tosca materialidad en la que se ahoga Occidente. A través de don Ramón, uno de los personajes principales de $\mathrm{La}$ serpiente emplumada, se expresa la idea, que irá desarrollándose a través 
de la novela, de que lo único que puede salvar a México de la situación en la que se encuentra no es el coqueteo con la modernidad, la técnica y el progreso a toda costa; por el contrario, la salvación de México, y a través de él quizá de la humanidad entera, solo puede provenir de su pasado más remoto, de ese mexicano profundo, anterior a todo contacto con Occidente, que aún sobrevive oculto en el mexicano de hoy.

En los himnos que el pueblo canta en las plazas y en los campos y que Kate escucha a lo lejos desde la puerta de su casa, se expresa la idea de una suerte de sustitución religiosa que ocurrió hace mucho tiempo y que ahora ha llegado el momento de su restitución: es el paso, en una primera instancia, de Quetzalcóatl a Jesús, la sucesión de las oraciones indígenas a las oraciones cristianas. Todo esto ocurre sin lucha, sin confrontación, sin violencia. Quetzalcóatl se sabe viejo, sin fuerza y acepta que ha llegado el momento de retirarse, de volver al cielo. Cede el trono en la Tierra a Jesús, su hermano, que ha sido enviado a México por su padre con una misión muy precisa: "Traeré la paz a México. Y vestiré al desnudo, y daré de comer al hambriento, y repartiré dones entre los necesitados y les daré paz y amor" (222). Quetzalcóatl desaparece de pronto volando entre el fuego de un volcán y México queda en las manos de Jesús.

Este sincretismo, esta sustitución religiosa es traducida por Juana, la sirvienta de Kate, en una fórmula no exenta de humor: "El señor es un gringo y su Santa Madre una gringuita [...] y vino por el mar como la niña, del país de la niña” (224). Ahora, según los himnos que el pueblo canta por las noches, es el momento del retorno de Quetzalcóatl. Jesús y su madre han fracasado en las tierras mexicanas, su mensaje de paz y amor no ha sido escuchado, no hablaba el mismo lenguaje del pueblo al que se dirigía. Los mexicanos, dice Jesús en los himnos,

son almas complicadas, llenas de rencores. Destrozaron mis templos, robaron mi fuerza, mancillaron los labios de la Virgen. Nos arrojaron de su seno y tuvimos que partir como un viejo decrépito y una pobre mujer agobiados por la edad y sin lágrimas. Huimos cuando no nos veían. Y solo buscamos descanso, olvidar a los hijos de los hombres que están envenenados con las piedras de la desesperación (227).

Jesús y María huyen de las tierras mexicanas donde su mensaje ha fracasado, donde nadie los escucha, donde sus palabras, por ser ajenas 
y extrañas a nuestra cultura, resultan ininteligibles. Es el momento en el que el relevo vuelve a establecerse, aunque en sentido contrario, la restitución de lo que, según Lawrence, siempre fue nuestro y en lo que sí podemos reconocernos: Quetzalcóatl regresa renovado. Ha rejuvenecido y recuperado su fuerza. Desde ahora él se hará cargo de estas tierras sin Dios, devoradas por la violencia y envenenadas por la desesperación. En su efímero reencuentro, Jesús le entrega a Quetzalcóatl el símbolo de su poder terrenal, que no le ha servido para nada y del que ha terminado expulsado: "Y en el borde del silencio [Jesús] se sentó [—-cuenta Quetzalcóatl-], se quitó las sandalias y yo me las puse" (226).

El primer mensaje de Quetzalcóatl a los mexicanos, su antiguo pueblo, es muy claro: por una parte, que le devuelvan a Jesús y a María todas sus imágenes y las de sus santos, y que abandonen los templos de ese Dios que nunca los escuchó. Y, por otra parte, que se laven, que se limpien la suciedad por dentro y por fuera, la del cuerpo y la del alma, que aprendan a ser hombres. Así, una nueva religión ha comenzado, la religión de Quetzalcóatl.

Está de más decir que el creador de los himnos del dios azteca es don Ramón, portavoz en la novela de las ideas mesiánicas de Lawrence, que se reúnen fundamentalmente en torno a un aspecto central: derramar sobre el pueblo de México el "espíritu nuevo", ese espíritu que debe conducir al pueblo mexicano hacia la "Estrella de la Mañana", de donde nace la "vida nueva”. Don Ramón Carrasco, en una entrevista con el obispo de la ciudad de México, es categórico en este sentido: "Hoy día, Padre, debemos hablar a los mexicanos en su propia lengua y dar con la palabra justa que pueda llegar a su alma. Yo la daré: Quetzalcóatl” (263).

A partir de ese momento, las relaciones entre la Iglesia católica y la Iglesia de Quetzalcóatl terminan volviéndose tensas, insostenibles: si los curas usan el sermón cotidiano para atacar a don Ramón, don Ramón hace lo mismo, en sentido contrario, desde la plaza pública y sus himnos. Hasta que una mañana de domingo los partidarios del dios azteca, armados de flautas y tambores, cruzan el portal exterior de la iglesia y entonan su "Despedida a Jesús" que es, al mismo tiempo, su bienvenida a Quetzalcóatl. Pero no es solo Jesús el que abandona la iglesia, también lo hace el sacerdote: entrega a don Ramón las llaves del templo, da su última bendición a los feligreses y se retira de la escena llevándose el santo crucifijo y todas las imágenes de vírgenes y santos. La iglesia queda en tinieblas. 
En una isla, a mitad del lago, don Ramón y el sacerdote les prenden fuego a todas esas imágenes. El cura arroja a la hoguera también su sotana, la sobrepelliz y la estola, y debajo de su vestimenta cristiana aparece ahora la blanca vestidura de los servidores de la nueva religión.

Como dominados por un éxtasis especial, los hombres atizaban la hoguera con madera resinosa que chisporroteaba al arder. [...] Todo el mundo se alejó de aquel racimo de llamas que subía a las mayores alturas llegando con el humo y las chispas hasta el mismo cielo. [...] Sayula estaba vacío, despojado de Dios. Y en el fondo, todos estaban contentos (286-287).

La conversión ha terminado por operarse. No solo don Ramón se ha ocupado de ella, sino el propio sacerdote cristiano ha participado entusiasmado en la ceremonia, como si de pronto descubriera que su verdadera esencia religiosa, que sus más profundas creencias, estaban inscritas en su antiguo pasado indígena y que hasta ahora solo habían sido acalladas, silenciadas, por esa religión europea que no tenía nada que ver con el profundo y verdadero sentir de los mexicanos. México ha sido devuelto, así, a las manos de su Dios original, esa mezcla esperpéntica de pájaro y reptil.

La nueva religión se ha apoderado definitivamente del espacio que la rodea y de los hombres que lo habitan. La iglesia, por ejemplo, ha cambiado las campanas por las flautas y los tambores: "Significa que no volverán a tocar las campanas. Las han quitado, y en la iglesia suenan ahora los tambores. Escuche. Escuche" (334). Pero no son solo las campanas las que han abandonado la iglesia, sino todos los símbolos cristianos: la cruz, la virgen María, Jesucristo y todo su corro de vírgenes y santos. Y, en su lugar, se erigen de pronto los símbolos de la nueva religión:

En el fondo del presbiterio brillaba una lucecilla azulada por encima del lugar que antes ocupaba el altar, y exactamente debajo, por delante de la lámpara, elevábase una enorme sombra, un bloque extraño de líneas indistintas que parecía estar esculpido en madera. Era la silueta de un hombre groseramente tallada y un poco aplastada; en el brazo derecho, levantado por encima de la cabeza, se posaba un águila con las alas desplegadas, cuya parte superior dorada brillaba a la luz de la lámpara [...]. Alrededor de la pierna derecha del hombre, una serpiente igualmente 
de oro brillante, cuya cabeza reposaba en la mano de la estatua, la cual dejaba caer sobre el muslo. El rostro del ídolo era negro (338-339).

Si las vírgenes y los santos han cedido el lugar al águila y a la serpiente, el dios blanco y postrado en la cruz de los europeos ha sido sustituido por la fuerte y vencedora figura del ídolo de rostro negro: un color de la piel y una expresión del rostro en los que, ahora sí, podrá reconocerse toda una raza hasta entonces vencida y sumisa al dios extranjero; desde ahora redimida y restituida a su fuerza y orgullo originales por el "nuevo espíritu" del dios Quetzalcóatl.

Si en don Ramón ha encarnado Quetzalcóatl, ${ }^{4}$ en Cipriano, su mano derecha, encarna también Huitzilopochtli, el dios indígena de la guerra. Pero toda religión, además de sus dioses masculinos, necesita también al menos una diosa. El matrimonio entre Kate y Cipriano dotará a la nueva religión de la diosa imprescindible. A pesar de algunas vacilaciones iniciales, Kate no solo acepta quedarse en México y casarse con Cipriano, sino también cambiar su nombre por el de la antigua diosa Malintzi. Con ello, no solo abandona su origen y su cultura europea, sino que se desdice de la racionalidad con la que ha interpretado el mundo hasta ahora para adoptar el nuevo misticismo redentor que deberá acompañarla en su nueva vida mexicana.

¿Qué es lo que provoca esa repentina conversión de Kate? ¿Qué es lo que hace que acepte ahora tan rápidamente lo que hasta ese momento había rechazado con firmeza: la sumisión y la indiferencia del indio mexicano, la delirante religión de Quetzalcóatl? No es otra cosa que la certeza de lo que le esperaría en la débil y exhausta Europa si decidiera volver a Inglaterra:

Pasearse por los salones de Londres para ser una muñeca más entre todos los esperpentos... Recobrar la mueca ridícula de todas las muñecas y el acento artificial de su voz... ¡Qué horror!

[...]

No me alejaré de Ramón ni de Cipriano porque gracias a ellos disfruto de la floración de la sangre. [...] Sin Cipriano para acariciarme, limitarme, aniquilar mi propia voluntad, me convertiría en una vieja

\footnotetext{
${ }^{4}$ Algunos críticos han sugerido que el personaje Ramón Carrasco está basado en la figura de Vasconcelos, no solo por la actitud mesiánica del pensador mexicano, sino porque en sus discursos solía presentarse como Quetzalcóatl redivivo (Anaya: 228-229).
} 
monstruosa. [...] Sí. Me someteré antes de convertirme en una vieja insoportable.

[...]

¿Para qué me voy a marchar? —díjose Kate—. ¿Por qué ir a ver los autobuses de Piccadilly la víspera de Navidad y la gente que mira los escaparates desde las aceras mojadas? Más valdría quedarme aquí donde mi alma no está tan solitaria. [...] No vacilaré. Después de todo aquí hay una grandeza inmensa en la llamada de los tambores de Quetzalcóatl (437-438).

A Kate, la vieja Europa no le ofrece nada que no conozca ya. Más bien, le ofrece exactamente lo mismo de lo que salió huyendo para refugiarse en México. ¿Cómo volver a los sofisticados salones de Londres y asumir la ridícula mueca de sus muñecas y la artificialidad de su voz? ¿Para qué volver a la plaza de Piccadilly a contemplar los mismos escaparates la víspera de Navidad? ¿Por qué aceptar convertirse en una vieja monstruosa e insoportable? Allí, la vida ha quedado atrapada en la grotesca y artificiosa caricatura que la técnica y las espurias convenciones sociales han hecho de ella. México, en cambio, posee la fuerza que hace posible la floración de la sangre, el surgimiento de un hombre libre y auténtico, es una tierra que despierta a la grandeza inmensa de la llamada de Quetzalcóatl. Es eso lo que a fin de cuentas la decide a aniquilar su voluntad y someterse a la fuerza interior, irracional y salvaje, de un hombre (Cipriano) y un pueblo (el México indígena), que constituyen el polo opuesto a la vieja y reblandecida racionalidad europea. Frente a esa racionalidad, que la convertiría en una muñeca ridícula, en un artificioso esperpento, elige la fuerza de la sangre, la fuerza oscura del sexo indígena, que harán de ella una mujer vital, verdadera, que la confirmarán en su deseo, en su cuerpo, en su voluntad de vivir. Desde ahora, los tambores de Quetzalcóatl latirán también en el corazón de Kate.

D. H. Lawrence consideró que La serpiente emplumada era la mejor novela que había escrito hasta entonces. La mayoría de sus críticos, sin embargo, no piensan lo mismo. Tampoco algunos de los escritores que le fueron contemporáneos. Si Aldous Huxley y Conrad Aiken lo consideraron siempre su mentor literario, T. S. Eliot y Gertrude Stein se refirieron a la obra de Lawrence como "mala literatura". Gertrude Stein, por ejemplo, en una conversación con Hemingway, una tarde le confesó: 
"Intenté leer sus novelas. No hay modo. Es sentimental e insensato y risible. Tiene un estilo de enfermo" (Hemingway: 33).

Muchos de los críticos que se han ocupado específicamente de $L a$ serpiente emplumada han terminado por calificarla como una novela fallida, una novela de tesis (la instauración de la nueva religión indígena que debe salvar a México, el regreso de los antiguos dioses, Quetzalcóatl y Huitzilopochtli, que traen consigo la regeneración de la sangre) que no resulta convincente; una novela sustentada en un mesianismo que solo responde a las fantasías utópicas de su autor, pero que no corresponde en lo más mínimo a la realidad que el escritor inglés tiene ante los ojos. Ya cité, en este trabajo, las opiniones de algunos de esos críticos en este sentido. Quiero concluir ahora con las palabras de F. R. Leavis que señalan justamente la gran deficiencia de la novela:

La evocación del renacimiento pagano nos causa la sensación de ser algo mecánico y planeado; en todo caso, es monótona y aburrida. Las descripciones de los ritos y las costumbres, de las danzas y las ceremonias, llenan enormes cantidades de páginas; $\mathrm{y}$ hay más páginas de cantos $\mathrm{e}$ himnos $[\ldots]$ que el lector tiende a saltarse. Es por medio de una especie de hechizo, por medio de un efecto hipnótico creado por el interminable latido de los tambores que desempeñan un papel tan importante en la campaña de Don Ramón, como Lawrence trata de convencernos; pero lo que logra producir es aburrimiento y mucha aversión.

[...]

Su supuesta convicción final, que ocurre al final de la obra cuando Kate decide quedarse en México y ser la esposa de Huitzilopochtli, no es convincente.

[...]

Más bien, esto indica el fracaso de Lawrence al tratar de convencerse a sí mismo de que esa superación podría haber sido lograda. Y por su constante y seria insistencia en este aspecto, The Plumed Serpent suena falsa (94-96).

Lawrence vino a México con una ilusión. No para escribir una novela, sino para inventarse una vida distinta. Esa ilusión no le permitió ver el México real y lo que sucedía en él: toda esa serie de circunstancias sociales, políticas, económicas, que harían imposible la construcción de su utopía. Si la realidad le impedía llevar a cabo su sueño mesiánico, ese sueño tendría que realizarse en otra parte. De ahí nace La serpiente 
emplumada: el espacio imaginario que la escritura hace posible le daría la oportunidad que la realidad le hurtaba. Y fue allí, en una novela, donde logró escenificar su sueño.

\section{BibLIOGRAFÍA}

Anaya Ferreira, Nair María. La otredad del mestizaje: América Latina en la literatura inglesa, México: Facultad de Filosofía y Letras, Universidad Nacional Autónoma de México, 2001, 381 pp.

Bergson, Henri. El pensamiento y lo moviente, Buenos Aires: La Pléyade, 1972, $188 \mathrm{pp}$.

Bynner, WitTer. Journey with Genius: Recolections and Reflections Concerning the D. H. Lawrence's, Nueva York: John Day, 1951.

Carballo, Emmanuel. "Prólogo" a D. H. Lawrence, Viva y muera México, México: Editorial Diógenes, pp. 9-17.

Hemingway, Ernest. Paris era una fiesta, Barcelona: Editorial Seix Barral, 1981, 208 pp.

Huxley, Aldous (comp.), The Letters of D. H. Lawrence, Nueva York: Viking, 1932.

Lawrence, D. H. La serpiente emplumada, Buenos Aires: Editorial Losada, 1940, $444 \mathrm{pp}$.

Lawrence, D. H. Mañanas en México, México: Letras de México, 1942, 157 pp.

Lawrence, D. H. Viva y muera México, México: Editorial Diógenes, 1970, 210 pp.

Lawrence, Frieda. Not I But the Wind..., Nueva York: Viking, 1934.

LeAvis, F. R. D. H. Lawrence, novelista, Barcelona: Barral Editores, 1974, 447 pp.

Moore, Harry T. (editor), The Collected Letters of D. H. Lawrence, Londres: Heinemann, 1962.

Ortega y Gasset, José. Pasado y porvenir para el hombre actual. Obras completas, Madrid: Editorial Revista de Occidente, 1971.

Parmenter, Ross. Lawrence en Oaxaca, México: Fondo de Cultura Económica, $1991,435 \mathrm{pp}$.

Ruffineldi, Jorge. El otro México, México: Editorial Nueva Imagen, 1978.

URroz, Eloy. Las formas de la inteligencia amorosa: D. H. Lawrence y James Joyce, Puebla: Secretaría de Cultura y Gobierno del Estado de Puebla, 1999.

Walker, Ronald G. Paraiso infernal. México y la novela inglesa moderna, México: Fondo de Cultura Económica, 1984, 337 pp.

Wayne Gunn, Drewey. Escritores norteamericanos y británicos en México, México: Fondo de Cultura Económica, 1977, 208 pp. 